\title{
O Diretor do Hospital - Leigo ou Médico?
}

\section{HUMBERTO BALLARINY}

$\mathrm{A}_{\mathrm{s}}$ opiniões divergem. Enquanto Goldwater defende $c$ ponto de vista do Diretor-médico, as escolas norte-americana e inglêsa, lideradas por MACEACHERN e STONE, não são da mesma opinião, voltando-se com maior simpatia para o administrador leigo.

As razõęs são compreensíveis, a nosso ver. Geralmente, os diretores dos hospitais do início da era contemporânea eram cirurgiões-chefes que continuavam operando e apenas assinavam ràpidamente o expediente, não tendo nem tempo nem conhecimentos de administração. Delegavam os encargos de gerência a alguém de sua confiança. Sentiu-se, porém, a necessidade de que se aperfeiçoassem, em virtude do desenvolvimento por que passavam as instituições hospitalares. Assim, criaram-se associações de administradores de hospitais e o próprio C.A.C. instituiu cursos oficiais para administradores hospitalares. Era uma profissão nova, que surgia sem as compensações financeiras que justificariam, por parte dc médico, o abandono do exercício de sua clínica, para dedicar-se, em tempo integral, a encargos absorventes e especializados .

O hospital moderno transformou se em conjunto de complexas instalações, provido de pessoal especializadc, cujos objetivos são prevenir, diagnos. ticar e tratar as doenças e traumatismos sofridos pelo organismo humano; facultar o ensino de conhecimentos médicos ou para médicos e promover pesquisas no sentido de ampliar os recursos da arte de evitar, curar ou mitigar os sofrimentos da humanidade.

Mas, o moderno conceito de assistência médicc-social transformou a administração hospitalar numa verdadeira ciência que requer do seu titular, no dizer do próprio MAC-EACHERN "uma larga educação, idoneidade em todos os sentidos, personalidade, filantropia, imaginação, espírito de iniciativa, habilidade administrativa, liderança, disciplina, tato, bom senso, coragem, lealdade, estabilidade emocional, senso de humor e amabilidade".

A educação vasta nada mais é do que uma sólida cultura geral e o enorme acervo de variados conhecimentos técnicas tais como: medicina, clínica cirúr. gica, saúde pública, especialidades médicas, estatística, sociologia, arquitetura, engenharia, direito administrativo e administração geral, que devem fazer parte da formação profissional do Diretor de Hcspital.

Assim sendo, poderíamos comparar o Hospital Geral dos nossos dias a uma grande orquestra sinfônica, executando uma sinfonia intitulada "preservação 
da saúde do homem". Ac maestro (diretor) cabe planejar, organizar, comandar, coordenar e controlar tôdas as operações subsidiárias para perfeita execução da partitura. O maestro não poderá reger uma orquetra sem conhecer todos os instrumentos. E' lógico que não necessita ser um exímio executor de tc.dos êles, porém não pode deixar de conhecê-los na sua essência. O organismo doente que procura o hospital é um instrumento a ser manipulado pelos mú. sicos (corpo-clínico). Poderá o maestro ser leigo em música (medicina)? Não ter passado pelo curso básico da faculdade, ou melhor não ter o diploma? Não ter, como músico (médico), enfrentado os percalços da arte de manusear os instrumentos (organismo), a fim de conhecer pràticamente os recursos a serem empregados para conseguir dos mesmos o melhor som (alta, curado)?

Não bastam a um Maestro (diretor) os dons artísticos natos, a capacidade de liderança, o conhecer o funcionamento e a fabricaçãc (anatomia e fisiologia) dos instrumentos, pois, se não conhecer música (medicina), êle não dirigirá a orquestra; não poderá comandar, coordenar e controlar os músicos executantes (corpo-clínico), conduzindo com êxito a emprêsa ao seu fim.

Mas, se, ao invés de uma crquestra sinfônica, tivermos um pequeno conjunto musical (hospitais pequenos), ou um grupo reduzido de instrumentos iguais (hospitais especializados), o músico mais experiente (Diretor Clínico), kuxiliado por um empresário ou gerente, conseguirá executar belíssimas partituras, com sucesso prcfissional.

O empresário gerente, que chamamos de administrador no último exemplo, não necessita ser diplomado em música, para administrar com eficiência a sociedade de músicos. Diríamos mesmo que a sua atuação eficiente permitiria ao músico chefe dedicar-se melhor ao prcblema musical, sem preocupações de natureza administrativa.

Como podemos ver, o administrador leigo é de grande utilidade. Assim, em pequenos hospitais de 100 leitos, em hospitais especializados onde o médico fundador é, ao mesmo tempo, o proprietário e o chefe do corpo clínico torna-se imprescindível o administrador leigo.

Nos grandes hospitais gerais também o administrador leigo, mas fcrmado em Adıninistração Hospitalar, é imprescindível na direção da Divisão Administrativa.

Assim, proporiamos uma terminclogia mais definida. O leigo com curso de Administração Hospitalar teria o título de Administrador Hospitalar. O Médico, especializado em Organização e Administração Hospitalar teria o título de Superintendente Hospitalar para diferenciá-lo do Diretor Clínico, que não necessitaria ter curso de organização.

Justificamos a terminologia de Superintendente e Administrador baseados nas definições do Dicionário de LAUDELINo FrEIRE:

Superintendente - inspecionar, vigiar ou dirigir com supervisão em matéria administrativa. Segundo citação de F.DE CASTRO - "ao Senhor Diretor que é quem deve superintender em matéria administrativa".

Diretor - que dirige, administra ou regula.

Administrador - o que tem a seu cargo a administração total ou parcial, o que administra, isto é, rege ou o ato de gerir. Preposto de proprietário na Hireção de fazenda ou sítio. 
Gerente - o que gere ou administra negócios, bens ou serviços .

Tanto o Administrador como o Superintendente, com o tirocínio adquirido no exercício de seus cargos e mediante estudos posteriores, poderão transformar-se em Consultores Hospitalares.

A finalidade máxima do hospital e da assistência médico-social moderna é a conservação da saúde física e mental do ser humano e o técnico mais categorizado dentre os que se dedicam a êsse mister é o médico.

Portanto, devemos reagir contra qualquer situação que possa deslocar a figura do médico na escala hierárquica daquelas atividades.

Atualmente, nos Estados Unidos, há uma tendência para considerar o médico ccmo uma visita do hospital. O Serviço de Enfermagem que deve ter, dentro do hospital, por motivos administrativos, uma chefia autônoma, freqüentemente se pavoneia; a enfermeira chefe se investe de uma exagerada importância; a ignorância da maicria dos médicos sôbre os modernos conceitos administrativos referentes aos serviços hospitalares, gerando em alguns urr.a men. talidade inadequada, não justifica o menosprêzo que alguns técnicos em organização hospitalar dispensam aos médicos do hospital.

A solução mais acertada seria, no currícul das escolas médicas, incluírom-se modernas noções sôbre assistência hospitalar, ao invés de permitir que ¿igos em medicina pretendam centralizar o comando, a coordenação e o contrôle de tôdas as operações técnico-administrativas executadas num hospital.

Um Diretor deve possuir:

a) cabeça - inteligência para planejar, improvisar e criar;

b) tronco - personalidade para dirigir, aliada a sólidos conhecimentos;

c) membros - capacidade de execução.

Conforme o ponto de vista de um leigo, Eulógio R. ANzA (R.P.H. II 5, p. 21), administrador hospitalar não-médico, um Diretor de hospital deve ser médico porque: clínico;

$\left.1^{\circ}\right)$ terá maiores facilidades para harmonizar as relações com o corpo

2. ${ }^{\circ}$ ) possuirá maior autoridade para considerar as necessidades técnicas médicas; públicas;

$3^{\circ}$ ) representará um fator de meridiana importância na relações

4. ${ }^{\circ}$ ) possuirá, fatalmente, maicr sedimentação de cultura social e médica; pital;

$5^{\circ}$ ) aumentará a confiança do corpo administrativo na direção do hos-

6. ${ }^{\circ}$ terá maior amplitude na imposição da liderança ao meio funcional do hospital;

7..$^{\circ}$ facilitará o trabalho ccordenado da equipe, assim como poderá estimular, ou mesmo despertar, mais fàcilmente, os desejos de cooperação;

8..$^{\circ}$ ) estará em condições de promover, de maneira mais corrpleta, a preparação do pessoal auxiliar; 
9..$^{\circ}$ um leigo formado em Administração Hcspitalar não pode prescindir de médico para supervisionar um Hospital; já a reciproca não é tão verdadeira".

E' de opinião que o leigo especializado em Administração Hospitalar deve ficar apenas com a Chefia da Divisão Administrativa, e que foram apenas a apatia e a indiferença médica as razões que colocaram em mãos leigas o órgão que configura el nervio del Hospital.

CORRÊA, Diretor de um Hospital Colônia para Tuberculosos (R.P.H. I vol. 1 n. ${ }^{\circ}$, p. 11), em artigo muito interessante, conta alguns casos pitorescos, bem adequados, nas suas soluçães, aos problemas enfrentados por um Diretor.

O Diretor deve ser um Homem de larga educação (MAC EACHERN) e segundo FLEXINER, trabalhar com inteligência e responsabilidade; está sempre ávido de ccnhecimentos, empregando sua perspicácia psicológica num campo mais prático do que especulativo, persuadindo e disciplinando graças a uma educação altamente especializada; é sempre um organizador pronto a identificar ou confundir os seus deveres com o interêsse público e o bem social, dotado de muito bom senso, com elevada média de decisões acertadas. Deve ser um bom comprador, conhecendo o mercado de preços além da qualidade de todos os milhares de artigos utilizados por um hospital; deve conhecer o funcicnamento do equipamento do hospital, a fim de aliar à habilidade de trabalhar com os outros, os ensinamentos que se fazem necessários; deve despertar o espírito de ccoperação, entusiasmando os seus subordinados e impondo-se à confiança de seus superiores; enfim: un.a personalidade cujas características serão a liderança, a honestidade, o sincero interêsse pela sua função.

JOSEPH DOANE, do American College of Surgeons, reclama do Diretor de um Hospital dez qualidades salvadoras, a saber:

1. $\left.{ }^{a}\right)$ Personalidade;

2. ${ }^{\text {a }) ~ P r e p a r a c ̧ a ̃ o ~ a d e q u a d a ~-~ E d u c a c ̧ a ̃ o ; ~}$

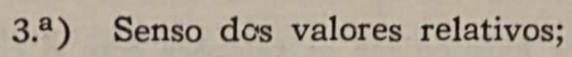

- 4. ${ }^{a}$ ) Bondade;

5. ${ }^{a}$ ) Bom senso ou bom julgamento;

6. ${ }^{\text {) }}$ Tato;

7. a) Capacidade de Liderança;

8. ${ }^{\text {a }) ~ H o n e s t i d a d e ~ i n t e l e c t u a l ; ~}$

9. $\left.{ }^{a}\right)$ Fé na educação;

10. $\left.{ }^{\mathrm{a}}\right)$ Boas maneiras.

\section{DEVERES DO SUPERINTENDENTE}

O Superintendente tem grandes responsabilidades e pesadas incumbências que o obrigam a assumir compromissos para com: a) a mesa administrativa; b) os funcionários; c) cs pacientes; d) a comunidade à qual o hospital presta serviços. 


\section{DEVERES DO SUPERINTENDENTE JUNTO À MESA ADMINISTRATIVA}

A Associação Americana de Hospitais e o Colégio Americano de Administradores de Hospitais, no seu código de ética aprovado e adotado em novembro de 1941, deınem as atribuições da mesa administrativa nos seguintes. itens:

a) Estudo das necessidades da comunidade a serem atendidas pela organização.

b) Prover o aparelhamento e os recursos necessários ao tratamento dos. doentes internados.

c) Fiscalizar para que o mclhor padrão de atendimento profissicnal seja mantido nos cuidados prestados ao doente.

d) Coordenar os interêsses profissionais com os administrativos, os finar. ceircs e com as necessiaades da comunidade.

e) Providenciar as verbas necessárias para a ampliação das instalações e equipan.entos imprescindíveis a um alto padrão hospitalar.

f) Providenciar as verbas de manutenção de modo a não faltar recursos. financeiros para perfeito funcionamento do hospital.

g) Manter um rigoroso contrôle do movimento contábil do hospital e uma fiscalização ativa de tôdas as atividades do hospital.

h) Cercar o paciente de tódas as proteções, pois é a referida mesa administrativa a responsável, moral e legal, pelo que se passar com o doente entregue aos cuidados do hospital. Assim sendo ela será responsável pela escolha, julgamento e seleção do Administrador, do Corpo Médico, da Enfermagem e de todo o corpo técnico do hospital; nesse julgamento não deve interferir o favoritismo, mas simplesmente o mérito individual do funcionário, julgado pela sua atuação profissional.

i) No exercício de suas funções nenhum membro da mesa administrativa. deve esperar proventos do hospital.

A Mesa Administrativa investe o Diretor das funções de execução e fiscalização do que foi estabelecido. O Diretor é responsável pelas verbas recebidas e sua aplicação e é o intermediário entre a M.A. e o corpo clínico e funcional do Hospital, assim como por tôdas as relações do hospital com a. comunidade na base da coordenação e cooperação.

Tendo em vista a competência da Mesa Administrativa e o fato de que o Superintendente é o seu executor, poderemos resumir os deveres dêstes para. com aquela nos seguintes itens:

$1^{\circ}$ ) Verificar se, de fato, o regulamento estabelecido vem sendo executado; cumpre-lhe, pois, conhecer bem todos os regulamentos, regimentos e rotinas, a fim de poder aplicá-los ao corpo clínico e ao pessoal do hospital.

$2^{\circ}$ ) Assistir a tôdas as reuniões do Conselho de Administração ou das. comissões nomeadas pelo Conselho, a fim de os auxiliar nas suas dúvidas.

$3^{\circ}$ ) Preparar o orçamento do hospital para um período futuro: receita despesa, caracterizando o deficit do trabalho não indenizado.

4. $\left.{ }^{\circ}\right)$ Fixar salários para os funcicnários subalternos, tendo completa autcridade para admiti-los ou demiti-los. 
5. ${ }^{\circ}$ ) Enviar relatórios periódicos a conselhos: a) mensais - movimento de doentes e riesultados de tratamento, situação financeira do hospital; b) anuais - atividades dos diversos departamentos.

6. ${ }^{\circ}$ Ressaltar os pontos não aceitáveis numa boa organização hcspitalar e sugerir meios para eliminá-los; por exemplo: planejando modificações de construçãc, reorganizando ou mesmo organizando novos serviçcs, que venham aumentar a eficiência do hospital.

$\left.7 .^{\circ}\right)$ Controlar tôdas as despesas do hospital, evitando por todos os meios os desperdícios; fiscalizar o material inutilizado; ter sob contrôle os restus de alimentos do hospital, e ter todo o material de consumo sob a responsabilidade dos seus chefes imediatos, que serão responsabilizados pelo seu gasto excessivo.

$8^{\circ}$ ) Providenciar o material, as instalações e equipamentc para o funcionamento dos diferentes departamentos.

9. $\left.{ }^{\circ}\right)$ Manter atualizado um mapa de contrôle estatístico e contábil de todos os setores, de modo a interpretar diàriamente o pulso do hospital.

\section{DEVERES DO SUPERINTENDENTE PARA COM OS FUNCIONÁRIOS}

1. Facilitar o treinamento do pessoal técnico e não técnico no cumprimento rigoroso das rotinas de serviço referentes aos serviços ou departamentos em que estiverem lotados.

2. Providenciar o bem estar físico, moral e intelectual dos funcionários através de:

a) exames de saúde ao serem admitidcs, seguidos de exames periódicos;

b) facilitar as atividades de caráter social entre os funcionários;

c) dispensar tratamento humanitário em todos os contatos que mantiver corr os mesmos;

d) promover cursos de especialização e treinamento para tôdas as categcrias funcionais do hospital;

e) trazer a biblioteca sempre atualizada;

f) constituir-se em sentinela dos direitos dos funcionários, e ao mesmo tempo em juiz enérgico e imparcial na aplicação das penas pelo não cumprimento dos deveres funcionais.

3. Coordenar os esforços dos diferentes departamentos, a fim de prevenir esforços inúteis; duplicação de tarcfas, perda de tempo, etc; o melhor recurso é estabelecer rotinas sempre atualizadas e beri: entrosadas, discutindo-as em reuniöes perićdicas, com os quadros departamentais.

4. Ser realmente um líder dentro da comunidade hospitalar, exercendo as suas faculdades de comando com firmeza, bondade, honestidade, justiça e habilidade administrativa; no exercício de suas funções deve antes guiar e crientar do que mandar os chefes e os técnicos.

5. Selecionar com sabedoria os seus chefes de serviços, de modo a delegar parcialmente as responsabilidades do bom funcionamento dos vários e complexos departamentos que constituem um hospital moderno.

6. Servir de ligação entre o Corpo Clínico e a Mesa Administrativa. 
DEVERES DO SUPERINTENDENTE PARA COM OS DOENTES

1. Verificar se o Corpo Clínico está cumprindo o regulamento e se os pacientes estão sendo tratados com eficiência.

2. Incentivar a assistência sćcial ao internado de modo a aliviá-lo das preocupações com os problemas sócio-econômicos.

3. Controlar a eficiência do tratamento do doente de ambulatório.

4. Cercar o paciente de tôda a proteção razoável de modo que aufira em tôda a plenitude os recursos que o hospital the possa oferecer, para a sua recuperação integral.

5. Facilitar aos dcentes a assistência religiosa que desejarem, evitando o constrangimento de um único sacerdote oficial nos quadros do hospital, a não ser que o hospital pertença e se destine apenas ao atendimento de adeptos de determinado culto religioso.

6. Por todos os meios e modos fazer respeitar o segrêdo profissional impondo confiança ao doente tratado no hospital. Em resumo, êle deve fiscalizar tôdas as fases de atividades do hospital, desde a lavagem de pratos até a avaliação do serviço profissional. 